\title{
Optimization of water-cement ratio in concrete contains recycled polypropylene (PP) plastic waste
}

\author{
Alaa Jaleel Naji ${ }^{1}$, Hayder Abbas Al-Yousefi ${ }^{2}$, Mohammed Abbas Mousa ${ }^{3}$, Murtadha Jasim Hussein ${ }^{4}$ \\ ${ }^{1}$ Road and Transportations Engineering Department, University of Al-Qadisiyah, Ad Diwaniyah, Iraq \\ ${ }^{2}$ Chemical Engineering Department, University of Al-Kufa \\ ${ }^{3}$ Road and Transportations Engineering Department, University of Al-Qadisiyah, Ad Diwaniyah, Iraq \\ ${ }^{4}$ Civil Engineering Department, University of Al-Qadisiyah, Ad Diwaniyah, Iraq
}

\begin{abstract}
Recently, the use of recycled plastic waste in civil engineering applications has been increased. This paper aims to investigate the effect of water-cement ratio on the compressive strength of concrete that contents $2.5 \%$ polypropylene (PP) as plastic waste. Two references concrete mixes were prepared. The first mix had a water-cement ratio of 0.45 with $2.5 \%$ plastic waste, the second mix with 0.45 water cement ratio but without plastic waste. Three concrete mixes with water cement ratios of $(0.5,0.4$, and 0.3$)$ were also used as parametric study cases. The results indicated that decreasing the water-cement ratio from 0.45 to 0.4 increases the compressive strength by $20.2 \%$. In addition, the compressive strength increases by $36.2 \%$ with decreasing of water cement ratio from 0.45 to 0.3 . While the compressive strength decreases by $12 \%$ with the increase of water-cement ratio from 0.45 to 0.5 .
\end{abstract}

Keywords:

Polypropylene; water-cement ratio; plastic waste; compressive strength

\section{Corresponding Author:}

Alaa Jaleel Naji

Assistant Lecturer, Road and Transportations Engineering Department

University of Al-Qadisiyah, Ad Diwaniyah, Iraq.

Email: alaa.alnsray@qu.edu.iq

\section{Introduction and Literature Review}

The expansion of global plastic consumption produces an increase in plastic waste which leads in turn to severe consequences on the environment. The process of plastic waste disintegration is taking a long time, and most components are toxic. So, reuse or recycling of plastic waste is preferred. plastic waste utilization in the concrete instead of fine aggregate has been studied by many researchers during the last years [1-7].

In 2012, Rai et al. carried out an experimental study focused on a plastic waste addition with ratios of $(0 \%$, $5 \%, 10 \%$, and 15\%) to normal concrete as a partial replacement of the sand with and without superplasticizer. Forty-eight cube specimens have been cast, six cubes were cast for each percentage of plastic waste without superplasticizer, and six cubes for each different percentages of plastic waste have been cast with superplasticizer. Compressive strength, dry density, fresh density, workability have been tested; the results indicated that the workability and compression strength were decreasing due to partial replacement of plastic waste. On the other hand, the superplasticizer enhanced the workability and compression strength, generally dry density and fresh density decreasing with the increase of plastic ratio in each concrete mixture [2].

In 2016, Ahmed researched the behavior of high performance concrete with using plastic waste ratios $(0 \%$, $2.5 \%, 5 \%$, and $7.5 \%$ ) as replacement from fine aggregate with partial replacement of silica fume as $10 \%$ of 
cement weight and addition superplasticizer [3]. The plastic waste type was Polyethylene Terephthalate (PET), some physical properties (bulk density, porosity, water absorption, and ultrasonic velocity) and mechanical properties (Compression strength, frictional tensile strength, flexural strength, and static elasticity modulus) have been tested. The results show some adverse effect on properties of high performance concrete which contents plastic waste such as reduction compression strength [3].

Vanitha et al. have carried out an experimental study incrementally added crushed plastic waste of high density Polyethylene (HDPE) with ratios of $(2 \%, 4 \%, 6 \%, 8 \%, 10 \%)$ as partial replacement for coarse aggregate of product paver blocks of size $(200 \mathrm{~mm} * 150 \mathrm{~mm} * 60 \mathrm{~mm})$ and solid blocks having a size (200 $\mathrm{mm} * 100 \mathrm{~mm} * 65 \mathrm{~mm})$ [4]. The compressive strength was tested at $(7,14,28)$ days. The researcher noticed the optimum content of plastic waste (HDPE) is $2 \%$ for solid blocks and $4 \%$ of paver block with marginal decreasing in compressive strength.

Rois et al. examined the useing of high performance structural concrete reinforced by polypropylene fibers in thermal energy storage systems [5]. These systems are susceptible for long exposition time at high temperatures, the behavior of the concrete at varying temperatures (hot tests) with $\left(100^{\circ} \mathrm{C}, 300^{\circ} \mathrm{C}, 500^{\circ} \mathrm{C}\right.$, $700^{\circ} \mathrm{C}$ ), cooled-down states (cold tests) and exposition times $(6,24,48)$ hour were a parametric. fracture behavior, the thermogravimetric analysis, Young's modulus, compressive strength, and tensile strength of concrete have been tested under different thermal conditions. The results indicated that once thermal, and moisture equilibrium are reached, exposition time does not have an effect on the mechanical properties of concrete.

The previous investigations were showed the optimum plastic waste ratio, $2.5 \%$ of aggregate, but these investigations don't show the effect of the water cement ratio on concrete mixes which content plastic waste, the present paper will study the effects of water cement ratio on the compression strength of concrete.

\section{Methodology}

In this study, the plastic waste (PP) have been collected from a recycling factory and then cut to different particle sizes (less than or equal to $4 \mathrm{~mm}$ ) of irregular shapes to be used as fine aggregates. Ordinary Portland cement was used in the concrete mixes [8]. Also, fine and coarse aggregates conform to the standard Iraqi specifications No. 45 have been used [14]. Thirty cubes were cast in the laboratory; Two mixes were reference depending on two parameters; the first parameter is the partial replacement of plastic waste; the second parameter is the water-cement ratio were three mixes showed changing in water-cement ratio. six cubes for each type of concrete mix with waste plastic ratio $2.5 \%$ as a partial replacement from fine aggregate with five different water-cement ratios as shown in Table (1). The laboratory tests were made for all mixes to determine compression strength and workability.

\section{Experimental test}

a. Workability: The workability of the fresh concrete was examined by using the slump test. The slump test was carried out in accordance with British Standards BS EN 12350-2, Testing fresh concrete [10].

b. Compressive strength: The compressive strength of the concrete was examined by testing concrete (30 cubes- 6 cubes for each mix). The test is implemented using a compressive testing machine having a $200 \mathrm{kN}$ capacity at a constant load rate of $0.5 \mathrm{MPa} / \mathrm{s}$ according to British Standards BS EN 12390-3:2009 [11].

\section{Results and discussion}

Table (1) indicates that the workability tends to increase with using plastic waste when the water-cement ratio is constant. However, the workability tends to decrease with decrease water cement ratio when the plastic waste ratio is constant.

(Fig. 1) observes that the compressive strength tends to increase with decrease water-cement ratio. The compressive strength for M3 mix is comparable to Ref. 1 mix as shown in Table 1. (Fig. 2) shows the 
compressive strength tends to decrease with using plastic waste when the water-cement ratio is constant, that is $(0.45)$.

\begin{tabular}{|r|r|r|r|r|r|r|r|r|}
\hline Mixes & $\begin{array}{r}\text { Cem. } \\
(\mathrm{kg})\end{array}$ & F. Agg. \\
$(\mathrm{kg})$ & $\begin{array}{r}\text { C. Agg. } \\
(\mathrm{kg})\end{array}$ & $\begin{array}{r}\text { W. Plastic } \\
(\mathrm{kg})\end{array}$ & W / C & $\begin{array}{r}\text { W /C } \\
\text { Ratio }\end{array}$ & $\begin{array}{r}\text { Slump } \\
(\mathrm{mm})\end{array}$ & $\begin{array}{r}\text { 28-day strength } \\
(\mathrm{Mpa})\end{array}$ \\
\hline Refer. 1 & 340 & 729 & 1110 & 0 & 153 & 0.45 & 20 & 34.45 \\
\hline Refer. 1 & 340 & 729 & 1110 & 18.22 & 153 & 0.45 & 35 & 25 \\
\hline M 1 & 340 & 710.77 & 1110 & 18.22 & 170 & 0.50 & 55 & 22 \\
\hline M 2 & 340 & 710.77 & 1110 & 18.22 & 136 & 0.40 & 25 & 30.05 \\
\hline M 3 & 340 & 710.77 & 1110 & 18.22 & 102 & 0.30 & 10 & 34.06 \\
\hline
\end{tabular}

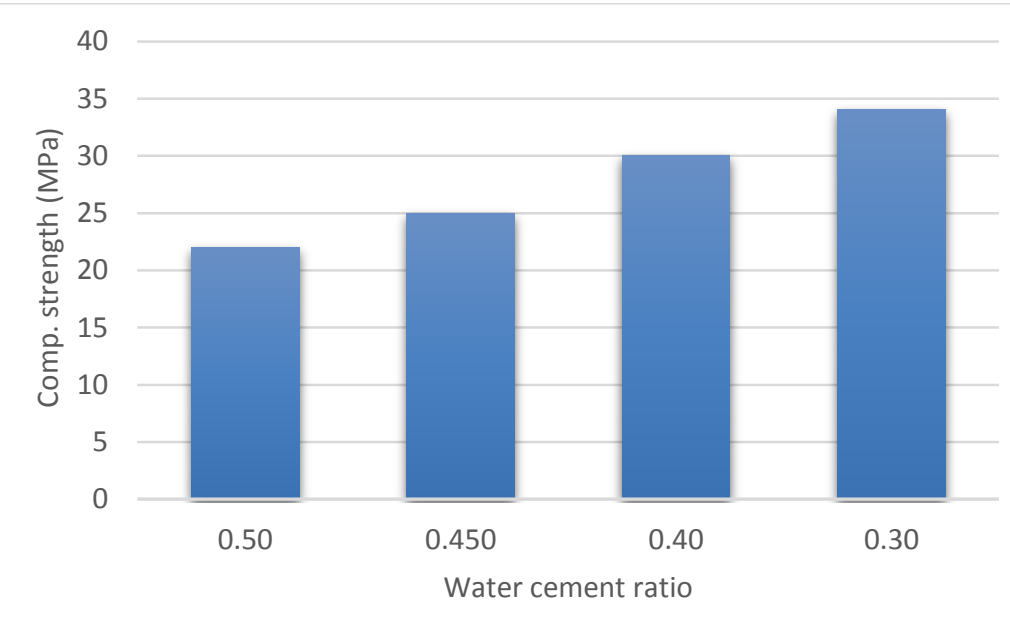

Fig. 1. W/C ratio with strength of concrete content $2.5 \%$ (PP) plastic waste.

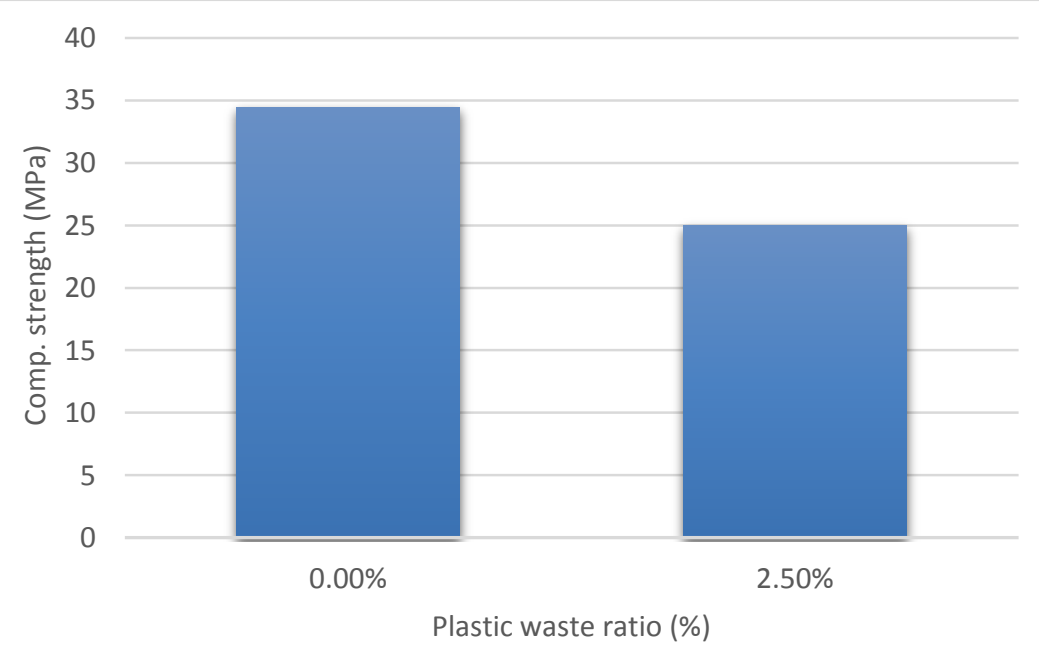

Fig. 2. Compressive strength plastic waste content $2.5 \%(\mathrm{PP})$ at $(0.45) \mathrm{W} / \mathrm{C}$ 


\section{Conclusion}

The results showed some adverse effects of the concrete that contain plastic waste such as decreasing compression strength. However, the compressive strength reduction can be accommodated by decrease watercement ratio taking into regard the concrete workability. The use of plastic aggregates provides some definite advantages such as the reuse of plastic waste as part of the fine aggregate used in the production of the concrete, also, opens a new horizon to reduce the cost of materials that used to produce the concrete as aggregate and solve some of the environmental problems by recycling plastic waste.

\section{References}

[1] A.M.S. and F.A.A.M. 1. M.R.A.A. Saleh Mohammed Qashout, Impacts of Plastic Wastes on Environmental and Human and Modern Ways to Take Advantage and Disposal, ISSN 2413-5267. 2015 (2015) 13.

[2] B. Rai, S.T. Rushad, B. Kr, S.K. Duggal, Study of Waste Plastic Mix Concrete with Plasticizer, ISRN Civ. Eng. 2012 (2012) 1-5. doi:10.5402/2012/469272.

[3] M.F. Ahmed, behavior high performance concrete by using plastic waste as fine aggregate, University of Baghdad,

2016. http://coeng.uobaghdad.edu.iq/?p=1737\&fbclid=IwAR2Eq_rhThdnzvWfYJPxsaMzliwhXYzPntXxByJl rxNvsqOoT7CBWzUzjgA.

[4] S. Vanitha, V. Natarajan, M. Praba, Utilisation of waste plastics as a partial replacement of coarse aggregate in concrete blocks, Indian J. Sci. Technol. 8 (2015). doi:10.17485/ijst/2015/v8i12/54462.

[5] J.D. Ríos, H. Cifuentes, C. Leiva, C. García, M.D. Alba, Behavior of high-strength polypropylene fiberreinforced self-compacting concrete exposed to high temperatures, J. Mater. Civ. Eng. 30 (2018). doi:10.1061/(ASCE)MT.1943-5533.0002491.

[6] Yasemin Akgün, Determination of Pozzolanic Activity for Using Natural Zeolite Analcime in Sustainability Additive Cement Products, periodicals engineering and nature science, Vol 5, No 2 (2017).

[7] Y.P.G. L.R. Bandodkar, A.A. Gaonkar, N.D. Gaonkar, Pulverised PET Bottles as Partial Replacement for Sand, Int. J. Earth Sci. Ans Enginering. 4 (2011) 1009-1012.

[8] Iraqi Specification, No.5, Portland Cement, in: Iraqi Specif., Iraqi Specifications, 1984.

[9] Kemal Turan, Green Materials and Applications, periodicals engineering and nature science, Vol 3, No 2 (2015).

[10] BS EN, BS EN 12350-2:2009 Testing fresh concrete. Slump-test, Br. Stand. Inst. (2009).

[11] BS EN, BS EN 12390-3 Testing Hardened Concrete: Compressive Strength of Test Specimens, Br. Stand. Inst. (2009).

[12] Gülden Çağın ULUBEYLİ, Turhan BİLİR and Recep ARTIR, Ceramic Wastes Usage as Alternative Aggregate in Mortar and Concrete, periodicals engineering and nature science, Vol 5, No 2 (2017).

[13] M. Faiz, Impact of Silica Fume on the Mechanical Properties of Recycled Aggregate Concrete, Eng. Sci. 36 (2009).

[14] Iraqi Specification, No.45, Aggregate from Natural Sources for Concrete and Construction, in: Iraqi Specif., 1984.

[15] İsmail Zorluer, Süleyman GÜCEK and Süleyman GÜCEK, Usage of Fly Ash and Waste Slime Boron for Soil Stabilization, periodicals engineering and nature science, Vol 5, No 1 (2017). 